\title{
Synthesis, Characterization and Performance Evaluation of Aceclofenac-Urea Cocrystals
}

\author{
S. KUMAR* A. GUPTA, C.K. MISHRA ${ }^{1}$ and S. SINGH \\ Goel Institute of Pharmacy and Sciences, Ayodhya Road, Lucknow, UP-226028, ${ }^{1}$ Birla Institute of Technology, Ranchi, \\ Jharkhand-835 215, India
}

Kumar et al.: Synthesis and Evaluation of Aceclofenac-Urea Cocrystals

\begin{abstract}
Aceclofenac is one of the commonly used Nonsteroidal anti-inflammatory drugs representing the variety of therapeutic applications including management of pain, inflammation, rheumatoid arthritis, and osteoarthritis, etc. But very low solubility and dissolution rate of aceclofenac compromise its therapeutic effectiveness. So, current work focuses on the improvement of solubility and dissolution of aceclofenac by the cocrystal approach. Aceclofenac was screened with various coformers selected from Generally Recognized as Safe and Everything Added to Foods in the United States list using Molecular orbital package 2016 software to find out novel cocrystals of aceclofenac with improved biopharmaceutical properties. Novel cocrystals of aceclofenac with urea were synthesized by mechanochemical grinding method. The synthesized cocrystals (Aceclofenac-Urea neat grinding and Aceclofenac-Urea liquid assisted grinding) were characterized carefully by Differential scanning calorimetry, infrared spectroscopy and powder $\mathrm{X}$-ray diffraction to verify the formation of the cocrystals. Pharmaceutically significant properties such as powder dissolution rate, solubility, and stability of the synthesized cocrystals were evaluated. Compared to aceclofenac, the synthesized cocrystals showed improved solubility and dissolution rate. The synthesized cocrystals were found to be non-hygroscopic and stable under ambient conditions.
\end{abstract}

Key words: Cocrystal, aceclofenac, mechanochemical synthesis, virtual screening, solubility study, bioavailability study

Aceclofenac (ACF) (2-[(2,6-dichlorophenyl)amino] phenylacetoxyacetic acid) is an orally effective Nonsteroidal anti-inflammatory drugs (NSAIDs), possessing significant anti-inflammatory, analgesic, and antipyretic properties ${ }^{[1,2]}$. ACF is useful in the treatment of pain, inflammation, rheumatoid arthritis, osteoarthritis, ankylosing spondylitis and other inflammatory diseases of the joints ${ }^{[3,4]}$. The time of maximum concentration observed $\left(\mathrm{T}_{\max }\right)$, mean plasma elimination half-life, the volume of distribution and relative oral bioavailability of aceclofenac are 1.5-3 h post-ingestion, $4 \mathrm{~h}, 251$ and $50 \%$ respectively ${ }^{[1,2]}$. ACF is proved as useful as other NSAID. It shows very few gastrointestinal adverse effects and thus, resulted in better compliance with disease management ${ }^{[5-7]}$. Being a Biopharmaceutical Classification System (BCS) Class-II drug (low solubility and high permeability), it exhibits very slight solubility in water, and as a consequence, it exhibits low oral bioavailability ${ }^{[8-12]}$. Therefore, the enhancement of ACF solubility and

*Address for correspondence

E-mail: visit2skumar@gmail.com

September-October 2020

Indian Journal of Pharmaceutical Sciences dissolution rate is a key issue for the enhancement of its bioavailability. In this context, it becomes important to explore the potential of novel formulation approaches in order to improve its solubility and dissolution rate.

Currently, various techniques like solid dispersion ${ }^{[13,14]}$, polymorphic $\quad$ changes $^{[15-17]}$ micronization ${ }^{[18]}$, Nanonization $^{[19-21]}, \quad$ Complexation $^{[22,23]}, \quad$ salt formation $^{[24-26]}$, emulsification ${ }^{[27]}$, solubilization ${ }^{[28]}$, and co-solvency ${ }^{[29]}$ etc., are being used by pharmaceutical scientists for enhancing the solubility and dissolution rate of drugs. From the recently published works, it is clear that cocrystallization has emerged as a novel technique for modulation of different physicochemical properties of drugg ${ }^{[30-37]}$. Cocrystals can vary in

This is an open access article distributed under the terms of the Creative Commons Attribution-NonCommercial-ShareAlike 3.0 License, which allows others to remix, tweak, and build upon the work non-commercially, as long as the author is credited and the new creations are licensed under the identical terms

Accepted 25 September 2020

Revised 11 September 2020

Received 21 April 2020

Indian J Pharm Sci 2020;82(5):881-890 
physicochemical properties when compared with their individual components, for example, their solubility, rate of dissolution, hygroscopicity, compressibility, flow property and other derived properties ${ }^{[38]}$. Pharmaceutical cocrystals of ACF with different coformers like Nicotinamide ${ }^{[39]}$, Chitosan ${ }^{[40]}$, Lysine ${ }^{[41]}$ and Gallic acid ${ }^{[42]}$ were recently reported.

In cocrystal synthesis, the choice of the suitable coformer is very important because it can influence the ultimate properties of the synthesized cocrystals ${ }^{[43-47]}$. In addition, coformer should be selected from Generally recognized as safe (GRAS) list, which ensures that it is safe for human utilization ${ }^{[48]}$. There are various methods that can be used for the selection of suitable coformer. In this work, the coformer screening process was performed by calculating excess heat of formation $\left(\Delta \mathrm{H}_{\mathrm{ex}}\right)$ of given stoichiometric $\mathrm{m}: \mathrm{n}$ mixtures using Molecular orbital package (MOPAC) software ${ }^{[49,50]}$. Several coformers like succinic acid, ascorbic acid, glutaric acid, D-glucosamine, pyridoxine, fumaric acid, nicotinamide, and urea, etc. were screened with the drug ACF. In this study, urea was selected as a coformer for the synthesis of aceclofenac cocrystal because it shows the highest negative $\mathrm{H}_{\mathrm{ex}}$ value.

Though various literatures describe various methods to obtain cocrystals in this study, the mechanochemical grinding method was adopted for the preparation of ACF cocrystals because this method is solvent-free, energyefficient, easily scalable and involves low operational $\cos ^{[51]}$. Various analytical techniques like infrared (IR) spectroscopy, Raman spectroscopy, Differential scanning calorimetry (DSC), X-ray diffraction (XRD), Scanning electron microscope (SEM), and solidstate Nuclear Magnetic Resonance (NMR), etc. were discussed in various literature for the confirmation of cocrystallization $^{[52,53]}$ (fig. 1).

Therefore, the aim of this study was to improve the solubility and dissolution rate of ACF by cocrystal approach. After a suitable coformer was selected, the cocrystals of ACF were synthesized by a neat grinding (NG) and liquid assisted grinding (LAG) technique. The characterization of synthesized product was done by Fourier transform infrared spectroscopy (FTIR), DSC, and powder X-ray diffraction (PXRD). After that, the synthesized cocrystals were subjected to solubility, dissolution, and stability studies.

\section{MATERIALS AND METHODS}

The drug ACF was obtained as a gift sample from Sigma-Aldrich, India. Urea was purchased from Central
Drug House $(\mathrm{CDH})$ fine chemicals, India. Methanol, Hydrochloric acid $(\mathrm{HCl})$, Potassium chloride $(\mathrm{KCl})$, were purchased from Rankem chemicals, India. All chemicals used were of analytical grade and they were used as received.

\section{Selection of coformer (Acid dissociation constant ( $\left.{ }^{\mathrm{ka}}\right)$ based method):}

All proposed coformers were chosen from the GRAS and Everything Added to Food in the United States (EAFUS) list. $\triangle \mathrm{pKa}$ value for each pair of $\mathrm{ACF}$ and proposed coformer was calculated. $\Delta \mathrm{pKa}$ value was used for the selection of potential coformers ${ }^{[54]}$.

\section{Selection of coformer (Virtual screening method):}

All molecules (ACF and all potential coformers chosen by pKa method mentioned above) were optimized using the PM7 semiempirical model utilizing the (conductorlike screening model for real solvents-COSMORS) approach. Based on obtained geometries heat of formation, dispersion energy, and hydrogen bond energy was calculated for all molecules individually and for pairs of ACF and each of potential coformers. All COSMO-RS calculations presented in this article were done with the help of MOPAC ${ }^{\circledR} 2016$ software.

The detailed procedure is illustrated as follows:

Step 1- Chemical structure of the selected drug was imported in Avogadro (version 1.2.0).

Step 2- The imported file was saved as .xyx file.

Step 3- This saved file (.xyz file) was open in Gabedit using a draw geometry option.

Step 4- MOPAC input file .mop was created by selecting appropriate functions (like charge, spin multiplicity, geometry optimization, hamiltonian and solvent type, etc.)

Step 5- The created .mop file was run in $\mathrm{MOPAC}^{\circledR} 2016$. This generates .out, .aux, arc and some other files as per the commands given during generation of .mop file

Step 6- Files generated by MOPAC ${ }^{\circledR} 2016$ can be opened by either note pad, Gabedit or Avogadro to get information about the heat of formation, Dispersion energy, and Hydrogen bond energy in given solvent (if any).

\section{Preparation of Aceclofenac and urea cocrystal:}

\section{Neat/Dry grinding method}

The accurately weighed drug and coformer, $708 \mathrm{mg}$ of ACF and $120 \mathrm{mg}$ of urea (1:1 molar ratio) were 
grounded in glass mortar-pestle for $30 \mathrm{~min}$. The powder Aceclofenac-Urea neat grinding (ACF-UREA NG) so obtained was collected and stored in a dessicator until further use.

\section{Liquid assisted grinding method}

The accurately weighed drug and coformer, $708 \mathrm{mg}$ of ACF and $120 \mathrm{mg}$ of urea (1:1 molar ratio) were grounded in glass mortar-pestle for $30 \mathrm{~min}$ with the aid of 2-3 drops of methanol. The powder AceclofenacUrea liquid assisted grinding (ACF-UREA LAG) so obtained was collected and stored in a dessicator until further use.

\section{Characterization and Evaluation of synthesized cocrystals:}

\section{Infrared spectroscopy}

For the pure drug, coformer and synthesized cocrystals, Fourier Transform Infrared (FT-IR) spectra were obtained. The spectrum was recorded in an IR-Prestige 21 (Shimadzu Corpn., Japan) spectrophotometer. The potassium bromide pellet method was used and the background spectrum was recorded under similar setting. Samples were scanned in the range of 400 $-4000 \mathrm{~cm}^{-1}$ at the spectral resolution of $1 \mathrm{~cm}^{-1}$.

\section{Powder X-ray diffraction studies}

The X-ray diffraction patterns of pure drug, coformer and synthesized cocrystals (ACF-UREA NG and ACFUREA LAG) were recorded using Rigaku Smart Lab 9kW (Rigaku, Japan) with $\mathrm{Cu}-\mathrm{Ka}$ radiation (1.540 $\AA$ ). All samples were scanned between $5-70^{\circ} 2 \theta$ with a step size of $0.01^{\circ}$. The operating conditions set were, $40 \mathrm{kV}$ voltage, $30 \mathrm{~mA}$ current, and $2 \%$ min scanning speed. All data was collected at ambient temperature. Before performing the experiments, the instrument was calibrated by means of a silicon standard.

\section{Thermal analysis by DSC}

For examination of the thermal behavior of drug alone and synthesized cocrystals (ACF-UREA NG and ACF-UREA LAG), DSC was conducted on a DSC 25 (Hewlett-Packard Company). 2-5 mg of the sample was kept in a $\mathrm{T}$ zero aluminum pans and then the pan was covered with a perforated aluminum lid and crimped by means of DSC crimper. The crimped aluminum pan containing the sample was kept in the thermal analysis chamber. An empty pan was used as a reference. The DSC instrument was calibrated for temperature using indium as a standard. Nitrogen gas was purged continuously at a flow rate of $30 \mathrm{ml} / \mathrm{min}$ for maintaining an inert atmosphere. Thermograms were obtained by heating the samples at a rate of $10^{\circ} / \mathrm{min}$ from $30^{\circ}$ to $350^{\circ}$. For better comparisons, DSC experiments were performed with almost identical amounts of samples.

\section{Evaluation of cocrystals:}

\section{Kinetic solubility study}

As equilibrium solubility becomes inappropriate if material converts from less stable form to more stable form during dissolution process in the gastrointestinal tract. As an alternative, intrinsic dissolution rate or kinetic solubility over a $10-12 \mathrm{~h}$ period may be more appropriate parameters to consider when studying the potential for enhanced oral absorption and bioavailability ${ }^{[55]}$. The kinetic solubility of pure drug ACF, physical mixture (PM) of the drug and UREA (ACF-UREA PM), and the synthesized cocrystals ACFUREA NG, and ACF-UREA LAG was measured in an acid buffer ( $\mathrm{pH} 1.2)$ by the shake flask method ${ }^{[56,57]}$. An excess $(5 \mathrm{mg} / \mathrm{ml})$ amount of powdered solids were placed in separate conical flasks containing $20 \mathrm{ml}$ buffer and distilled water. These conical flasks were placed in a mechanical shaker, maintained at ambient temperature $\left(25^{\circ}\right)$. Aliquots $(0.5 \mathrm{ml})$ of the sample were taken out at different time intervals for a period of $48 \mathrm{~h}$ to verify that the solution has achieved equilibrium. Withdrawn samples were filtered by $0.45 \mu \mathrm{m}$ Whatman filter paper, diluted suitably, and quantified by High performance liquid chromatography (HPLC) at $276 \mathrm{~nm}$. The quantity of drug dissolved in each time interval was calculated with the help of the calibration curve (linearity range: $4-20 \mu \mathrm{g} / \mathrm{ml}$ ) which was prepared in a HCL buffer $(\mathrm{pH}$ 1.2). The experiment was performed in triplicate and values were presented as mean \pm standard deviation.

\section{In-vitro dissolution rate study}

The in-vitro dissolution studies of the pure drug ACF, physical mixture ACF-UREA PM, and the synthesized cocrystals ACF-UREA NG, and ACF-UREA LAG were carried out using 8 Station Indian Pharmacopoeia (IP) type-2 dissolution apparatus (Microprocessor dissolution test apparatus-1918, Electronics India (EI), India $)^{[9,58]}$. Accurately weighed powders corresponding to (for cocrystal or physical mixture) $100 \mathrm{mg}$ of ACF was added to dissolution vessels. The in-vitro dissolution profile was examined in $900 \mathrm{ml}$ buffer $(\mathrm{pH} \mathrm{1.2)}$ from 0 to $1 \mathrm{~h}$. Baskets were rotated at a constant speed of 
$50 \mathrm{rpm}$. The medium was maintained at $37^{\circ} \pm 0.5^{\circ}$. Aliquots of samples were withdrawn after every $10 \mathrm{~min}$, and the same volume of fresh medium was added immediately to the test medium. The amount of drug dissolved at various time intervals was then measured by taking the absorbance at $276 \mathrm{~nm}$ using HPLC. Percent cumulative drug dissolved from the powdered samples was then calculated from the calibration curve (linearity range: $4-20 \mu \mathrm{g} / \mathrm{ml}$ ) which was prepared in a HCL buffer $(\mathrm{pH} 1.2)$, and a plot of time (min) vs. percent cumulative drug dissolved was plotted. The experiment was performed in triplicate and values were expressed as mean \pm standard deviation.

\section{Hygroscopicity and long-term stability testing}

In this study, degree of hygroscopicity of the synthesized cocrystals was measured by a method provided in European Pharmacopoeia ${ }^{[59]}$. For measurement of degree of hygroscopicity, $200 \mathrm{mg}$ sample of synthesized cocrystals was placed into open and tarred plastic petriplates and then these plates were kept into a desiccator (maintained at ambient temperature and $80 \pm 2 \%$ Relative Humidity (RH)) for $24 \mathrm{~h}$. The weight of the samples was taken by after $24 \mathrm{~h}$ of storage to verify the water uptake by samples.

For estimation of long-term stability of synthesized cocrystals about $200 \mathrm{mg}$ of pure drug ACF, physical mixture ACF-UREA PM, and the synthesized cocrystals ACF-UREA NG, and ACF-UREA LAG were placed in an open Petri dish and stored in a Remi SC-6 stability chamber (Rami laboratories Instruments, Mumbai, India). The temperature and humidity were maintained at $40^{\circ}$ and $75 \% \mathrm{RH}$ respectively (as per the World Health Organization (WHO)/International Conference on Harmonisation (ICH) guidelines) for $6 \mathrm{mo}^{[11,60-62]}$. The stability and integrity of the samples were assessed by DSC and PXRD methods.

\section{RESULT AND DISCUSSION}

Many previous studies revealed that difference in the $\mathrm{pKa}[\Delta \mathrm{pKa}=\mathrm{pKa}$ (base) $-\mathrm{pKa}$ (acid) $]$ value of the reacting species can be used in predicting formation of salts or cocrystals. In the pharmaceutical industry the rule of thumb for salt formation is a $\mathrm{pKa}$ difference greater than 3 and for cocrystal formation is less than 3 . Following 15 potential cocrystal formers were chosen on the basis of calculated $\Delta \mathrm{pKa}$ value (Table 1). All the chosen coformers have the potential to form cocrystal with ACF because calculated $\Delta \mathrm{pKa}$ values for each pair is less than 3 which is in favor of cocrystal formation.
COSMO-RS theory developed by Klamt A at Bayer $\mathrm{AG}$, is a general theory to predict the thermodynamic equilibrium properties of liquids. This theory takes into account the most important modes of molecular interactions, electrostatics, hydrogen bonding, and Vander Waals interactions ${ }^{[63-65]}$. According to this theory, the difference between the heat of formation of the pure components and the corresponding heat of formation for the cocrystal provides a measure of the thermodynamic driving force for cocrystal formation. A Negative Heats of reaction- $\mathrm{H}_{\mathrm{EX}}$ value indicates a high probability of cocrystal formation and shows cocrystals are all more stable than the precursors.

$\mathrm{H}_{\mathrm{EX}}$ to form cocrystals can be calculated by subtracting the heats of formation of the components (in their solidstate) from the heat of formation of the cocrystal.

$\mathrm{H}_{\mathrm{EX}}=\mathrm{Hcc}-\mathrm{H}_{\mathrm{API}}-\mathrm{H}_{\mathrm{CF}}$ (1). Where $\mathrm{H}_{\mathrm{API}}, \mathrm{H}_{\mathrm{CF}}$ and Hcc are the heat of formation of pure API, pure coformer, and cocrystal, respectively. The results of the calculated heat of formations of ACF, potential coformers, and proposed cocrystals are shown in Table 2. From the calculated $\mathrm{H}_{\mathrm{EX}}$ value it can be concluded urea has the good probability to form cocrystal with aceclofenac. Optimized geometry of proposed ACF-urea cocrystal along with possible hydrogen bonds is given as follows (fig. 2).

The FT-IR spectra of ACF, urea and formed cocrystals ACF-UREANGandACF-UREALAGof their respective combination (fig. 3 and fig. 4) in the stoichiometric ratio of 1:1 were analyzed and represented in the Table 3. In the FT-IR spectrum of the pure drug ACF,

TABLE 1: $p^{\text {ka }}$ VALUE OF DRUG, COFORMER, AND CALCULATED $\Delta p^{k a}$ VALUES

\begin{tabular}{|c|c|c|c|c|}
\hline API & API $p^{k a}$ & Coformer & $\begin{array}{c}\text { Coformer } \\
\mathrm{p}^{\mathrm{ka}}\end{array}$ & $\Delta \mathrm{p}^{\mathrm{ka}}$ \\
\hline \multirow{16}{*}{ Aceclofenac } & \multirow{16}{*}{4.7} & $\begin{array}{c}\text { 4-hydroxybenzoic } \\
\text { acid }\end{array}$ & 4.6 & 0.1 \\
\hline & & Cinnamic acid & 4.4 & 0.3 \\
\hline & & Succinic acid & 4.16 & 0.54 \\
\hline & & Ascorbic acid & 4.1 & 0.6 \\
\hline & & Lactic acid & 3.86 & 0.84 \\
\hline & & Urea & 0.1 & 4.6 \\
\hline & & Glycolic acid & 3.83 & 0.87 \\
\hline & & Isonicotinamide & 3.61 & 1.09 \\
\hline & & Fumaric acid & 3.55 & 1.15 \\
\hline & & Malic acid & 3.4 & 1.3 \\
\hline & & Nicotinamide & 3.35 & 1.35 \\
\hline & & Saccharin & 2.2 & 2.5 \\
\hline & & D- Glucosamine & 7.58 & 2.88 \\
\hline & & l-Cystine & 1.71 & 2.99 \\
\hline & & Pyridoxine & 5.58 & 0.88 \\
\hline & & Glutaric acid & 4.34 & 0.36 \\
\hline
\end{tabular}

September-October 2020 
peaks at $1728.28 \mathrm{~cm}^{-1}, 3070.78 \mathrm{~cm}^{-1}$, and $3319.60 \mathrm{~cm}^{-1}$ can be assigned to $\mathrm{C}=\mathrm{O}$ and $\mathrm{O}-\mathrm{H}$ stretching of the carboxylic acid functional group and N-H stretching. In the FT-IR spectrum of ACF-UREA NG, the peak of $\mathrm{C}=\mathrm{O}$ and $\mathrm{O}-\mathrm{H}$ stretching of the carboxylic acid functional group has been shifted to $1718.63 \mathrm{~cm}^{-1}$ and $2937.68 \mathrm{~cm}^{-1}$, respectively, when compared with the pure drug. In the FT-IR spectrum of ACF-UREA LAG, the peak of $\mathrm{C}=\mathrm{O}$ and $\mathrm{O}-\mathrm{H}$ stretching of the carboxylic acid functional group has been shifted to 1724.42 $\mathrm{cm}^{-1}$ and $2937.68 \mathrm{~cm}^{-1}$ respectively. The decrease in frequencies implies that the $\mathrm{C}=\mathrm{O}$ and $-\mathrm{OH}$ group of ACF have participated in strong hydrogen bond formation with urea. Hence, confirming the formation of the cocrystals.

PXRD is a very useful technique for the preliminary characterization of new solid forms as well as cocrystals. In each case, freshly synthesized powder samples were used for the data collection. The PXRD patterns of the pure drug ACF, coformer, and the synthesized cocrystals were plotted in fig. 5 and fig. 6. PXRD pattern of the synthesized cocrystals exhibited a change in both the number and intensity of peaks compared to pure $\mathrm{ACF}$ and coformer indicating the formation of a new crystalline phase.

The obtained DSC curves for the drug, the cocrystal formers and the formed cocrystals were analyzed and represented in fig. 7 and fig. 8. In the case of the pure drug ACF, a sharp peak was obtained at $152.04^{\circ}$. The cocrystal formers urea showed sharp peaks at $134.83^{\circ}$ and $203.99^{\circ}$. The cocrystal of ACF and urea in the stoichiometric ratio of 1:1 showed a peak at $104.57^{\circ}$ in case of ACF-UREA NG and at $104.12^{\circ}$ in case of ACFUREA LAG which were different from the drug as well as the cocrystal former and these shifting indicates the formation of new crystalline forms.

The kinetic solubility profile of ACF, ACF-UREA PM, ACF-UREA LAG and ACF-UREA NG are illustrated in fig. 9. It was observed that cocrystallization significantly enhances the solubility of ACF. It was observed that the transient solubility of ACF and its cocrystals after $6 \mathrm{~h}$ follows the rank order: ACF-UREA NG (5.91 times) $>$ ACF-UREA LAG (3.74 times) $>$ ACFUREA PM (1.21 times)>ACF (Table 4). Fascinatingly,

TABLE 2: CALCULATED HEAT OF FORMATION OF ACECLOFENAC, POTENTIAL COFORMERS AND PROPOSED COCRYSTALS

\begin{tabular}{lcccc}
\hline Drug & Coformer & $\mathrm{H}_{\mathrm{CF}}$ & $\mathrm{H}_{\mathrm{CC}}$ & $\mathrm{H}_{\mathrm{EX}}$ \\
\hline & I-Cystine & -176.41 & -362.33 & -35.395 \\
& Pyridoxine & -113.32 & -296.05 & -32.194 \\
& D- Glucosamine & -227.04 & -408.68 & -31.112 \\
& Urea & -51.108 & -219.61 & -17.97 \\
& Nicotinamide & -22.541 & -188.15 & -15.084 \\
& Isonicotinamide & -21.301 & -184.52 & -12.688 \\
& Glycolic acid & -139.92 & -301.12 & -10.672 \\
Aceclofenac & -150.53 & -119.23 & -278.82 & -9.0539 \\
& 4-hydroxybenzoic acid & -168.27 & -327.41 & -8.6092 \\
& Fumaric acid & -58.625 & -216.8 & -7.6441 \\
& Cinnamic acid & -238.84 & -396.92 & -7.5517 \\
& Malic acid & -201.92 & -358.91 & -6.457 \\
& Succinic acid & -225.02 & -381.97 & -6.415 \\
& Ascorbic acid & -94.729 & -251.34 & -6.0869 \\
& Saccharin & -207.89 & -364.42 & -5.9976 \\
& Glutaric acid & -151.17 & -2.6137 \\
\hline
\end{tabular}<smiles>O=C(O)COC(=O)Cc1cccc(Nc2c(Cl)cccc2Cl)c1</smiles>

Aceclofenac<smiles>NC(N)=O</smiles>

Urea

Fig. 1: Chemical Structure of Aceclofenac and Urea 


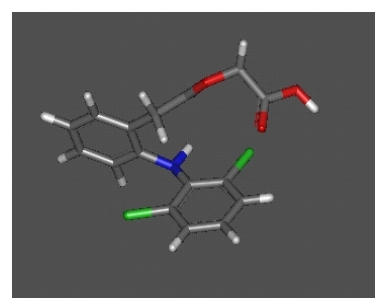

Aceclofenac

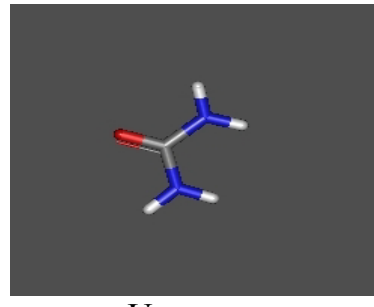

Urea

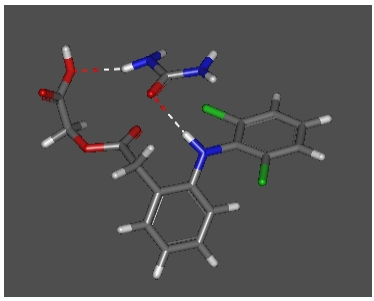

Aceclofenac-Urea cocrystal

Fig. 2: Optimized geometries of Drug, Coformer, and drug with coformer along with possible hydrogen bonds

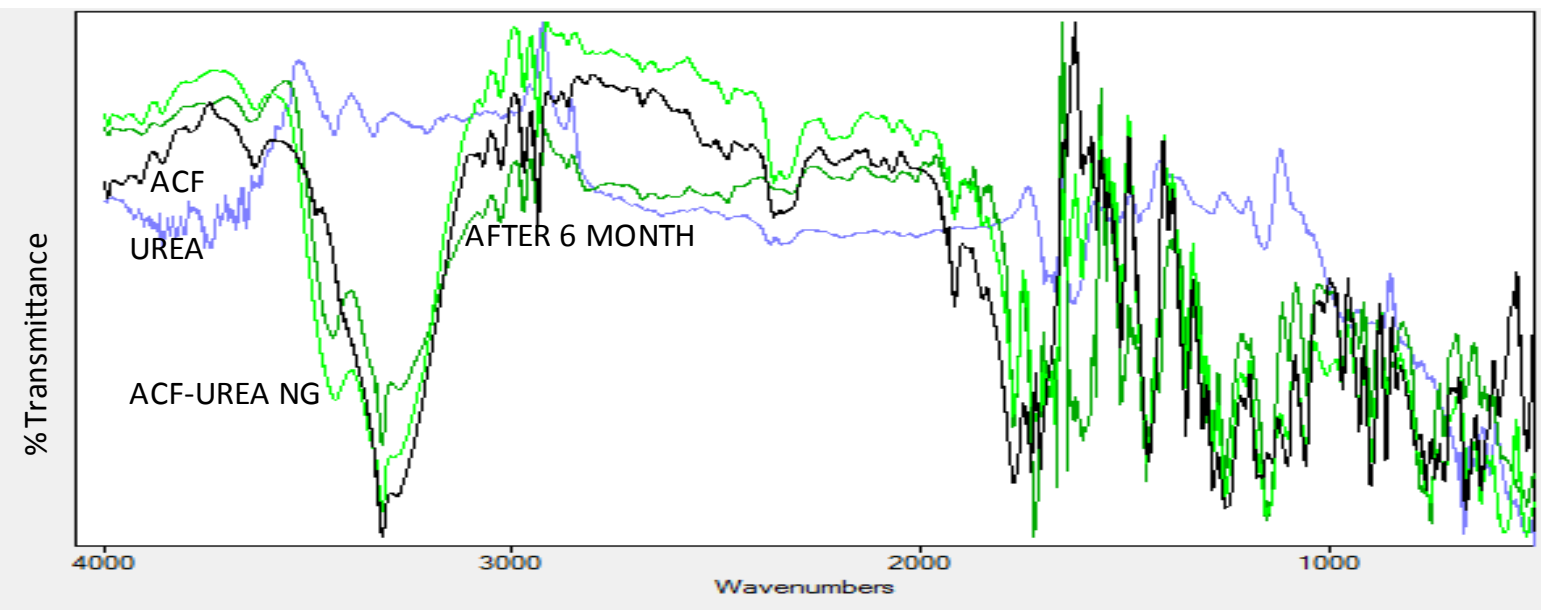

Fig. 3: FTIR spectra of Aceclofenac, Urea, ACF-UREA NG cocrystals synthesized freshly and after 6 mo

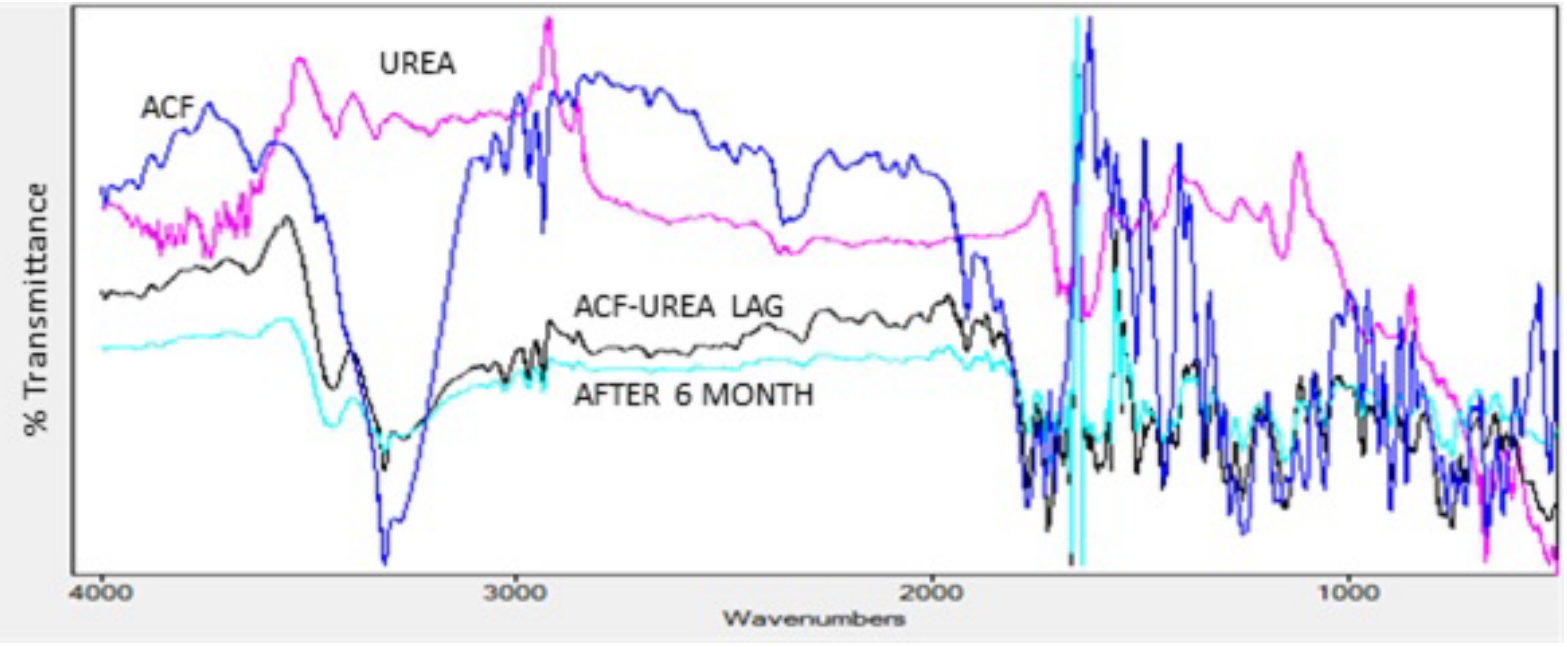

Fig. 4: FTIR spectra of Aceclofenac, Urea, ACF-UREA LAG cocrystals synthesized freshly and after 6 mo

our results show that ACF-UREA NG has the highest transient solubility.
The in-vitro dissolution rate of the synthesized cocrystals was one of the main criteria to evaluate performance of 
TABLE 3: COMPARISON FTIR SPECTRUM OF ACECLOFENAC AND PREPARATIONS

\begin{tabular}{lcccc}
\hline \multirow{2}{*}{ Interpretation } & $\mathrm{N}-\mathrm{H}$ stretching $\left(\mathrm{cm}^{-1}\right)$ & $\mathrm{O}-\mathrm{H}$ stretching & \multirow{2}{*}{$\mathrm{C}=\mathbf{O}$ stretching $\left(\mathrm{cm}^{-1}\right)$} & $\mathrm{C}-\mathrm{Cl} \mathrm{stretching}\left(\mathrm{cm}^{-1}\right)$ \\
\cline { 3 - 4 } & & $\left(\mathrm{cm}^{-1}\right)$ & 1728.28 & 1057.03 \\
\hline ACF & 3319.6 & 3070.78 & 1718.63 & 1057.03 \\
ACF-UREA NG & 3319.6 & 2937.68 & 1724.42 & 1055.1 \\
ACF-UREA LAG & 3319.6 & 2937.68 & \\
\hline
\end{tabular}

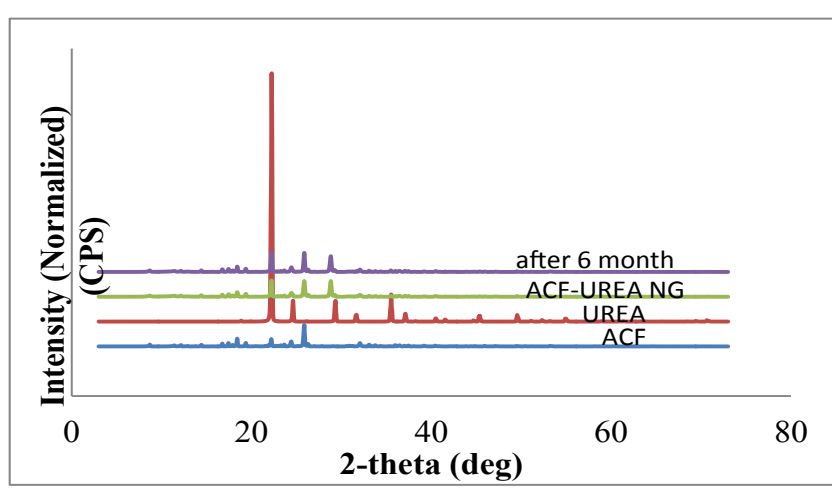

Fig. 5: X-ray diffraction graph of Aceclofenac, urea, ACFUREA NG cocrystals synthesized freshly and after 6 mo

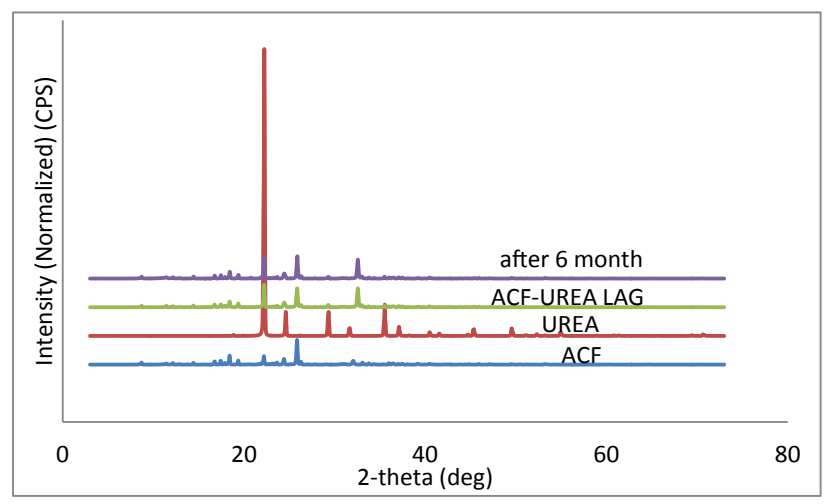

Fig. 6: X-ray diffraction graph of Aceclofenac, urea, ACFUREA LAG cocrystals synthesized freshly and after 6 mo

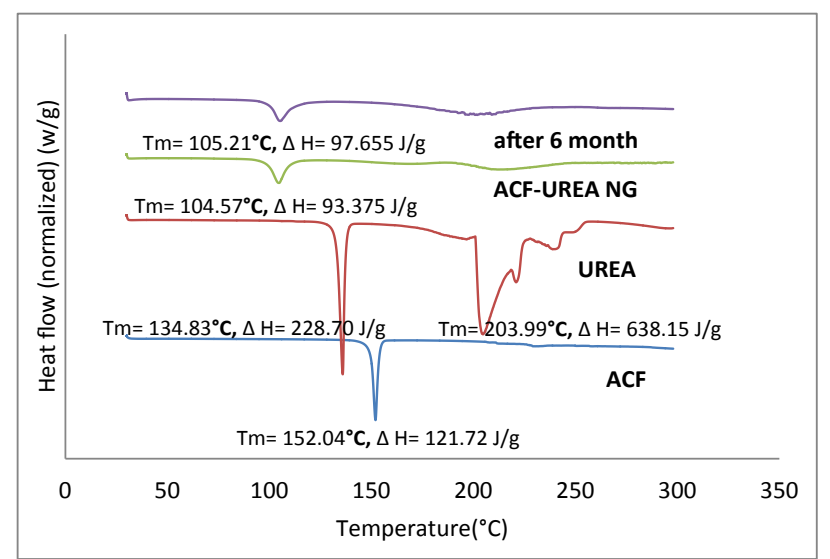

Fig. 7: DSC scans of Aceclofenac, urea, ACF-CYS NG cocrystals synthesized immediately and after 6 mo

cocrystals. For this reason, the percent cumulative drug dissolved was calculated for the pure drug, physical mixture, and synthesized cocrystals in $\mathrm{HCl}$ buffer $\mathrm{pH}$ 1.2 (Table 5) and their dissolution profiles were shown

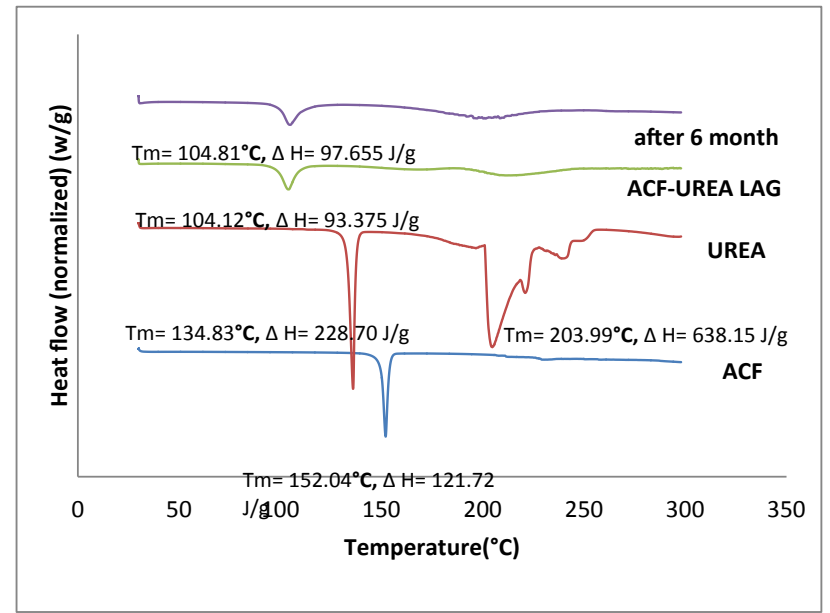

Fig. 8: DSC scans of Aceclofenac, urea, ACF-CYS LAG cocrystals synthesized immediately and after 6 mo

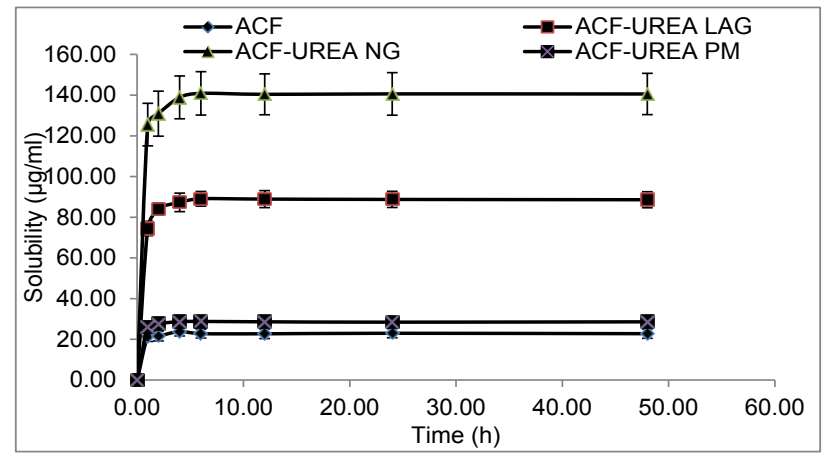

Fig. 9: Solubility of Aceclofenac, Physical mixture, and synthesized cocrystals

in fig. 10. From the results of this study, it can be evidently seen that the percentage of cumulative drug dissolved is improved in the case of the cocrystals. This indicates the effect of change in the crystal structure of ACF induced during cocrystallization on its dissolution rate. Inclusion of urea probably improved the wettability of hydrophobic surface and reduced the crystal lattice energy which is a main requisite for drug dissolution. The dissolution rate is fastest in the case of ACF-UREA NG which reaches $97.36 \%$ in 30 min only. This profile is important because a larger concentration of drug can be achieved at the absorption site. The observation suggested that synthesized cocrystals with an improved dissolution rate would potentially improve gastrointestinal (GI) absorption and onset action of ACF. 
TABLE 4: KINETIC SOLUBILITY OF ACECLOFENAC AND VARIOUS PREPARATIONS IN DISTILLED WATER AND HCL BUFFER pH 1.2

\begin{tabular}{lcc}
\hline \multirow{2}{*}{ Sample Name } & Transient Solubility after 6 h & Increase in \\
\cline { 2 - 3 } & $(\mu \mathrm{g} / \mathrm{ml}) \pm$ S.D. & solubility \\
\hline ACF (Distilled Water) & $27.69 \pm 1.42$ (after $48 \mathrm{~h})$ & $\cdots$ \\
ACF (HCl buffer pH 1.2) & $22.80 \pm 2.22$ & $\cdots$ \\
ACF-UREA PM (HCl buffer pH 1.2) & $28.79 \pm 2.51$ & 1.21 times \\
ACF-UREA LAG (HCl buffer pH 1.2) & $89.07 \pm 3.59$ & 3.74 times \\
ACF-UREA NG (HCl buffer pH 1.2) & $140.89 \pm 10.65$ & 5.91 times \\
\hline
\end{tabular}

TABLE 5: DISSOLUTION PROFILE OF ACECLOFENAC, PHYSICAL MIXTURE, AND SYNTHESIZED COCRYSTALS

\begin{tabular}{ccccc}
\hline \multirow{2}{*}{ Time $(\min )$} & \multicolumn{4}{c}{ \% cumulative drug dissolved \pm S.D. } \\
\cline { 2 - 4 } 0 & ACF \pm S.D. & ACF-UREA NG & ACF-UREA LAG & ACF-UREA PM \\
10 & $0.00 \pm 0.00$ & $0.00 \pm 0.00$ & $0.00 \pm 0.00$ & $0.00 \pm 0.00$ \\
20 & $15.23 \pm 0.41$ & $81.08 \pm 3.82$ & $71.56 \pm 5.10$ & $26.45 \pm 0.58$ \\
30 & $16.75 \pm 0.49$ & $95.53 \pm 4.27$ & $80.12 \pm 5.73$ & $30.66 \pm 3.22$ \\
40 & $17.10 \pm 0.87$ & $97.36 \pm 3.04$ & $82.86 \pm 4.49$ & $32.09 \pm 2.82$ \\
60 & $18.64 \pm 1.00$ & $98.47 \pm 1.80$ & $82.85 \pm 4.61$ & $36.08 \pm 2.56$ \\
\hline
\end{tabular}

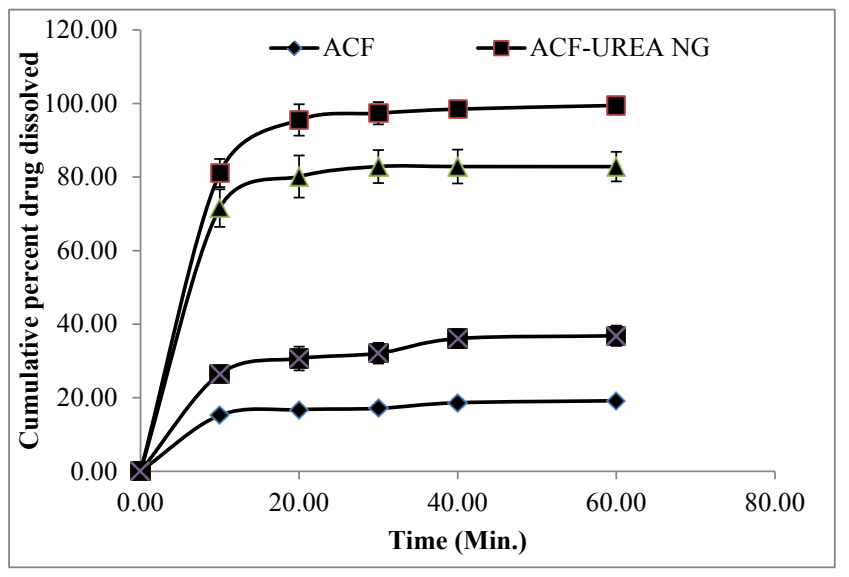

Fig. 10: Comparison of dissolution profile of Aceclofenac, Physical mixture, and synthesized cocrystals

As percentage of increase in mass of the samples remains unchanged throughout the study period (24 h), it was concluded that both the cocrystals were non-hygroscopic at ambient temperature $\left(27^{\circ} \mathrm{C}\right)$ and RH $80 \%$. Cocrystals kept in stability chamber were evaluated for the physical stability using DSC and PXRD methods. Comparison of PXRD (fig. 5 and fig. 6) patterns and DSC Pattern (fig. 7 and fig. 8) of cocrystals after 6 mo shows no change in either peak intensity or peak position, indicates good physical stability of synthesized cocrystals.

The use of cocrystals is an emerging trend to improve the physicochemical properties of the Active Pharmaceutical Ingredient (API). In this research work, cocrystallization was explored to address the solubility and dissolution rate issues of ACF. The knowledge of $\Delta \mathrm{pKa}$ and heat of formation to create a new cocrystal has been successfully utilized in this research work. ACF urea cocrystals were synthesized by neat grinding method and solvent-drop grinding method. Synthesized cocrystals were characterized by FT-IR, PXRD and DSC methods. The characterization results established the formation of the novel cocrystal. From this research work, it can be established that $\Delta \mathrm{pKa}$ and heat of formation calculations can be used for screening of potential coformer. ACF and urea can form a cocrystal by neat grinding and solvent-drop grinding method. The synthesized cocrystal showed enhancement in solubility and dissolution which is essential for achieving improved bioavailability. Moreover, synthesized cocrystals were found to be non-hygroscopic and stable for $6 \mathrm{mo}$ at ambient conditions and therefore these cocrystals present a chance to develop the combination drug of ACF with urea.

\section{Acknowledgements:}

Authors are thankful to vice-chancellor Dr. A.P.J. Technical University, Lucknow, Uttar Pradesh, India for his sustained encouragement, meticulous supervision and valuable suggestions at all stages of completion of this manuscript. The authors are also thankful to Er. Mahesh Goel, Managing Director, Goel Institute of Pharmacy \& Sciences, Lucknow, Uttar Pradesh, India for providing the laboratory and library facilities to complete current research work. The authors are also thankful to CIF, BIT-Mesra, Ranchi (India), for IR, DSC, and PXRD analysis and providing necessary facilities for this work. 


\section{Conflict of Interests:}

The authors report no conflicts of interest. The authors alone are responsible for the content and writing of this article.

\section{REFERENCES}

1. Aceclofenac-DrugBank. Go.drugbank.com; 2020.

2. Moffat AC, Osselton MD, Widdop B. Clarke's Analysis of Drugs and Poisons. $4^{\text {th }}$ ed. London; Gurnee, III: Pharmaceutical Press; 2011:813.

3. Somberg J. Martindale: The complete drug reference. Am J Ther 2005; 12(5):472.

4. Moore RA, Derry S, McQuay HJ. Single dose oral aceclofenac for postoperative pain in adults. Cochrane Database Syst Rev 2009(3).

5. Dooley M, Spencer CM, Dunn CJ. Aceclofenac: a reappraisal of its use in the management of pain and rheumatic disease. Drugs 2001;61(9):1351-78.

6. Brogden RN, Wiseman LR. Aceclofenac. A review of its pharmacodynamic properties and therapeutic potential in the treatment of rheumatic disorders and in pain management. Drugs 1996;52(1):113-24.

7. Pareek A, Chandurkar N. Comparison of gastrointestinal safety and tolerability of aceclofenac with diclofenac: A multicenter, randomized, double-blind study in patients with knee osteoarthritis. Curr Med Res Opin 2013;29(7):849-59.

8. Vadher AH, Parikh JR, Parikh RH, Solanki AB. Preparation and characterization of co-grinded mixtures of aceclofenac and neusilin US 2 for dissolution enhancement of aceclofenac. AAPS PharmSciTech 2009;10(2):606-14.

9. Verma S, Nanda A, Basu SP. Improvement of solubility and bioavailability of aceclofenac using cocrystallization. Drug Invent Today 2019;11(1):59-63.

10. Chandel N, Gupta V, Pandey A, Saxena S. Co-crystalization of aceclofenac and paracetamol and their characterization. Int $\mathrm{J}$ Res Dev Pharm Life Sci 2011;2(8):1020-28.

11. Goud NR, Suresh K, Nangia A. Solubility and stability advantage of aceclofenac salts. Cryst Growth Des 2013;13(4):1590-601.

12. Sohrab M, Mahapatra SP, Tiwari S. Enhancement of dissolution rate of aceclofenac by formation of aceclofenacnicotinic acid cocrystal using water soluble polymers like PVPK-30, HPMCE5, SSG and Na-CMC. Indo Glob J Pharm Sci 2015;5(3):154-70.

13. Abdul-Fattah AM, Bhargava HN. Preparation and in vitro evaluation of solid dispersions of halofantrine. Int $\mathrm{J}$ Pharm 2002;235(1-2):17-33.

14. Paudwal G, Rawat N, Gupta R, Baldi A, Singh G, Gupta PN. Recent advances in solid dispersion technology for efficient delivery of poorly water-soluble drugs. Curr Pharm Des 2019;25(13):1524-35.

15. Liebenberg W, de Villiers MM, Wurster DE, Swanepoel E, Dekker TG, Lotter AP. The effect of polymorphism on powder compaction and dissolution properties of chemically equivalent oxytetracycline hydrochloride powders. Drug Dev Ind Pharm 1999;25(9):1027-33.

16. Moribe K, Tozuka Y, Yamamoto K. Supercritical carbon dioxide processing of active pharmaceutical ingredients for polymorphic control and for complex formation. Adv Drug Deliv Rev 2008;60(3):328-38.
17. Martin CR. Crystal engineering approaches to controlling the formation of molecular complexes and their polymorphs. Thesis; 2012.

18. Rasenack N, Steckel H, Müller BW. Micronization of antiinflammatory drugs for pulmonary delivery by a controlled crystallization process. J Pharm Sci 2003;92(1):35-44

19. Liu P. Nanocrystal formulation for poorly soluble drugs. Helsingin yliopisto; 2013.

20. Park JJ, Meghani N, Choi JS, Lee BJ. Development and evaluation of decorated aceclofenac nanocrystals. Colloids Surf B Biointerfaces 2016;143:206-12.

21. Merisko-Liversidge E, Liversidge GG, Cooper ER. Nanosizing: a formulation approach for poorly-water-soluble compounds. Eur J Pharm Sci 2003;18(2):113-20.

22. Cugovcan M, Jablan J, Lovric J, Cincic D, Galic N, Jug M Biopharmaceutical characterization of praziquantel cocrystals and cyclodextrin complexes prepared by grinding. J Pharm Biomed Anal 2017;137:42-53.

23. Wen $X$, Tan F, Jing Z, Liu Z. Preparation and study the $1: 2$ inclusion complex of carvedilol with $\beta$-cyclodextrin. J Pharm Biomed Anal 2004;34(3):517-23

24. Basavoju S, Bostrom D, Velaga SP. Pharmaceutical cocrystal and salts of norfloxacin. Cryst Growth Des 2006;6(12):2699708

25. Vioglio PC, Chierotti MR, Gobetto R. Pharmaceutical aspects of salt and cocrystal forms of APIs and characterization challenges. Adv Drug Deliv Rev 2017;117:86-110.

26. Reddy LS, Bethune SJ, Kampf JW, Rodriguez-Hornedo N. Cocrystals and salts of gabapentin: $\mathrm{pH}$ dependent cocrystal stability and solubility. Cryst Growth Des 2009;9(1):378-85.

27. Kawabata Y, Wada K, Nakatani M, Yamada S, Onoue S Formulation design for poorly water-soluble drugs based on biopharmaceutics classification system: basic approaches and practical applications. Int J Pharm 2011;420(1):1-10.

28. Huang N, Rodriguez-Hornedo N. Effect of micellar solubilization on cocrystal solubility and stability. Cryst Growth Des 2010;10(5):2050-3.

29. Chen X, Fadda HM, Aburub A, Mishra D, Pinal R. Cosolvency approach for assessing the solubility of drugs in poly (vinylpyrrolidone). Int J Pharm 2015;494(1):346-56.

30. Shan N, Zaworotko MJ. The role of cocrystals in pharmaceutical science. Drug Discov Today 2008;13(9-10):440-6.

31. Perlovich GL, Manin AN. Design of pharmaceutical cocrystals for drug solubility improvement. Russ J Gen Chem 2014;84(2):407-14.

32. Almarsson $\mathrm{O}$, Peterson $\mathrm{ML}$, Zaworotko $\mathrm{M}$. The $\mathrm{A}$ to $\mathrm{Z}$ of pharmaceutical cocrystals: a decade of fast-moving new science and patents. Pharm Pat Anal 2012;1(3):313-27.

33. Schultheiss N, Newman A. Pharmaceutical cocrystals and their physicochemical properties. Cryst Growth Des 2009;9(6):2950-67.

34. Ghadi R, Ghuge A, Ghumre S, Waghmare N, Kadam VJ. Cocrystals: emerging approach in pharmaceutical design. Am J Pharm Res 2014;4.

35. Qiao N, Li M, Schlindwein W, Malek N, Davies A, Trappitt G. Pharmaceutical cocrystals: An overview. Int J Pharm 2011;419(1-2):1-11.

36. Korotkovaa EI, Kratochvil B. Pharmaceutical Cocrystals. Procedia Chem 2014;10:473-76.

37. Shan N, Zaworotko MJ. The role of cocrystals in pharmaceutical science. Drug Discov Today 2008;13(9-10):440-6.

38. Bolla G, Nangia A. Pharmaceutical cocrystals: walking the 
talk. Chem Commun 2016;52(54):8342-60.

39. Sevukarajan M, Thanuja B, Sodanapalli R, Nair R. Synthesis and characterization of a pharmaceutical co-crystal:(aceclofenac: nicotinamide). J Pharm Sci Res 2011;3(6):1288-93.

40. Ganesh M, Jeon UJ, Ubaidulla U, Hemalatha P, Saravanakumar A, Peng MM, et al. Chitosan cocrystals embedded alginate beads for enhancing the solubility and bioavailability of aceclofenac. Int J Biol Macromol 2015;74:310-7.

41. Sharma G, Saini MK, Thakur K, Kapil N, Garg NK, Raza K, et al. Aceclofenac cocrystal nanoliposomes for rheumatoid arthritis with better dermatokinetic attributes: a preclinical study. Nanomedicine 2017;12(6):615-38.

42. Verma S, Nanda A, Basu SP. Screening, preparation, and characterization of aceclofenac cocrystals. Drug Invent Today 2019;11(1):81-7.

43. Kotak U, Prajapati V, Solanki H, Jani G, Jha P. Cocrystallization technique its rationale and recent progress. World J Pharm Pharm Sci 2015;4(4):1484-508.

44. Manin AN, Voronin AP, Drozd KV, Manin NG, Bauer-Brandl A, Perlovich GL. Cocrystal screening of hydroxybenzamides with benzoic acid derivatives: a comparative study of thermal and solution-based methods. Eur J Pharm Sci 2014;65:56-64.

45. Douroumis D, Ross SA, Nokhodchi A. Advanced methodologies for cocrystal synthesis. Adv Drug Deliv Rev 2017;117:178-95.

46. Shan N, Perry ML, Weyna DR, Zaworotko MJ. Impact of pharmaceutical cocrystals: the effects on drug pharmacokinetics. Expert Opin Drug Metab Toxicol 2014;10(9):1255-71.

47. Issa $\mathrm{N}$. Towards more efficient screening of pharmaceutical cocrystals (Doctoral dissertation, UCL (University College London)); 2011.

48. SCOGS (Select Committee on GRAS Substances). U.S. Food and Drug Administration; 2020.

49. Heats of Reaction forming Co-Crystals. Openmopac.net; 2020.

50. Oliveira MA, Peterson ML, Davey RJ. Relative enthalpy of formation for co-crystals of small organic molecules. Cryst Growth Des 2011;11(2):449-57.

51. Braga D, Maini L, Grepioni F. Mechanochemical preparation of co-crystals. Chem Soc Rev 2013;42(18):7638-48.

52. De Almeida AC, Torquetti C, Ferreira PO, Fernandes RP, dos Santos EC, Kogawa AC, et al. Cocrystals of ciprofloxacin with nicotinic and isonicotinic acids: mechanochemical synthesis, characterization, thermal and solubility study. Thermochim Acta 2020;685:178346.
53. Abidi SS, Azim Y, Gupta AK, Pradeep CP. Mechanochemical synthesis and structural characterization of three novel cocrystals of dimethylglyoxime with $\mathrm{N}$-heterocyclic aromatic compounds and acetamide. J Mol Struct 2017;1150:103-11.

54. Silva Filho SF, Pereira AC, Sarraguça JM, Sarraguça MC, Lopes J, de Freitas Façanha Filho P, et al. Synthesis of a Glibenclamide cocrystal: full spectroscopic and thermal characterization. J Pharm Sci 2018;107(6):1597-604.

55. Singhal D, Curatolo W. Drug polymorphism and dosage form design: a practical perspective. Adv Drug Deliv Rev 2004;56(3):335-47.

56. Reggane M, Wiest J, Saedtler M, Harlacher C, Gutmann $\mathrm{M}$, Zottnick SH, et al. Bioinspired co-crystals of Imatinib providing enhanced kinetic solubility. Eur J Pharm Biopharm 2018;128:290-9.

57. Blokhina S, Sharapova A, Ol'khovich M, Perlovich G. Thermodynamic study of aceclofenac solubility, distribution and sublimation. J Chem Thermodyn 2019;137:13-21.

58. Mathur V, Satrawala Y, Rajput MS. Biopharmaceutical performance and stability of co-crystal. Int J Pharm Front Res 2011;1(1):135-45.

59. Murikipudi V, Gupta P, Sihorkar V. Efficient throughput method for hygroscopicity classification of active and inactive pharmaceutical ingredients by water vapor sorption analysis. Pharm Dev Technol 2013;18(2):348-58.

60. Healy AM, Worku ZA, Kumar D, Madi AM. Pharmaceutical solvates, hydrates and amorphous forms: A special emphasis on cocrystals. Adv Drug Deliv Rev 2017;117:25-46.

61. Trask AV, Motherwell WS, Jones W. Physical stability enhancement of theophylline via cocrystallization. Int J Pharm 2006;320(1-2):114-23.

62. Ullah M, Hussain I, Sun CC. The development of carbamazepine-succinic acid cocrystal tablet formulations with improved in vitro and in vivo performance. Drug Dev Ind Pharm 2016;42(6):969-76.

63. Loschen C, Klamt A. COSMOtherm as a Valuable Tool for Cocrystal Screening and Development. CosmoLogic; 2013.

64. Loschen C, Klamt A. Solubility prediction, solvate and cocrystal screening as tools for rational crystal engineering. J Pharm Pharmacol 2015;67(6):803-11.

65. Cysewski P. In silico screening of dicarboxylic acids for cocrystallization with phenylpiperazine derivatives based on both cocrystallization propensity and solubility advantage. J Mol Model 2017;23(4):136. 